\title{
Cluster Hiring Is Working for Us: Two Early Career Latinas in Math
}

\section{Selenne Bañuelos and Cynthia Flores}

\section{Note: The opinions expressed here are not necessarily those of Notices.}

During the 2013-2014 academic year 1,926 PhDs were awarded in mathematics in the USA. Five of those PhDs $(0.26 \%)$ were awarded to Latina US citizens [Vélez]. We, Selenne Bañuelos and Cynthia Flores, are two out of those five PhD awardees, and we were hired together as assistant professors in mathematics at California State University Channel Islands beginning in fall 2014. We have been successful due to our shared commitment to working at an institution like ours, joint experiences in professional development, and the value placed on us by our colleagues and students. This article will discuss the impact that being hired together has had on us, our students, and our university.

\section{About CSU Channel Islands}

California State University Channel Islands (CSUCI), located in Camarillo, California, was founded in 2002 and is the newest campus in the largest public university system

Selenne Bañuelos is an assistant professor of mathematics at California State University Channel Islands. Her email address is selenne. banue1os@csuci.edu.

Cynthia Flores is an assistant professor of mathematics at California State University Channel Islands. Her email address is cynthia.flores@ csuci .edu.

Communicated by Notices associate editor Stephan Ramon Garcia.

For permission to reprint this article, please contact: reprint-permission aams.org.

DOI: https://dx.doi.org/10.1090/noti1937 in the United States. CSUCI is the result of a forty-year effort to bring a public four-year university to the Ventura County region and currently enrolls more than 7,000 students. The university is a designated Hispanic-Serving Institution (HSI), where the student body is 53\% underrepresented minority (Hispanic, African American/Black, Native American/Alaskan): 50\% are Hispanic, $49 \%$ are Pell Recipients, $64 \%$ are female, and 59\% are first-generation college students.

\section{How We Were Hired}

The description that follows depicts the novel approach for recruitment and hiring that CSU Channel Islands engaged in during the 2013-2014 academic year. All departments were asked to submit requests during fall 2013 for positions to be filled with a start date in fall 2014. The positions were then approved by the administration. All approved positions followed the same hiring timeline regardless of disciplinary culture or practices. The due date for the applications occurred after the Joint Mathematics Meetings (JMM), and thus we were not interviewed during the 2014 JMM. This hiring practice is different from what is generally followed in the mathematics discipline.

Candidates from different (in this case, thirteen) disciplines were invited to an on-campus interview. Candidates for each position were reviewed by their respective Disciplinary Search Committees (DSC), one such hiring committee per open position. Our DSC included all mathematics tenure-track faculty, along with one biology faculty 


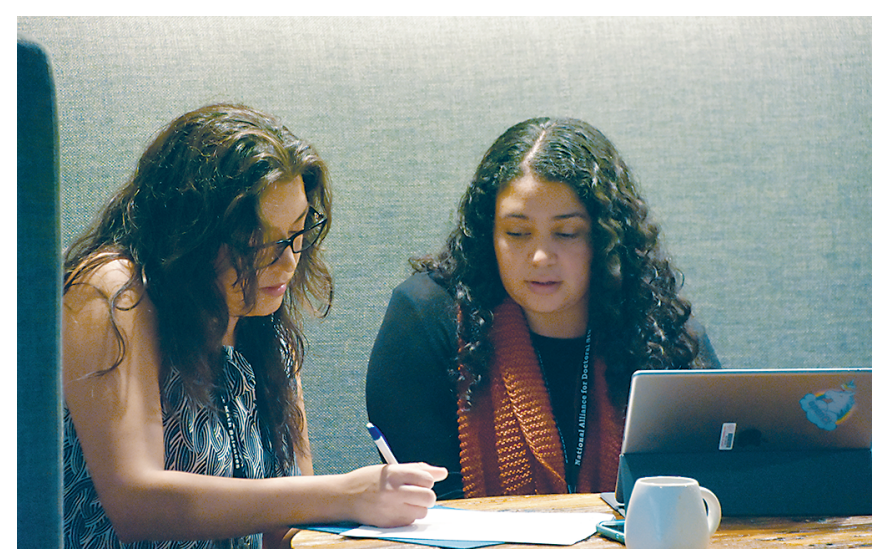

Figure 1. Selenne (left) and Cynthia (right) work together at the 2017 Field of Dreams Conference.

member and one history faculty member. Generally, to avoid seeing multiple candidates from the same discipline on one date, the process is extended over three weeks. The university faculty, students, staff, and administration were involved in the recruitment and hiring process. In particular, the Faculty Search Coordinating Committee, an elected committee from the Faculty Senate of the Whole, worked closely with Academic Affairs to coordinate our two-day on-campus visit. We gave talks (some disciplines ask for both a research presentation and a teaching demonstration) where all were welcome to attend. We participated in interdisciplinary discussions with candidates across disciplines and were interviewed by our DSC and by administrators, including the provost and president. We had many opportunities to meet with faculty from different disciplines during several networking activities. Although the DSC put forth the hiring recommendations, members of the administration made the final decision. Through this process CSUCI hired seventeen faculty to join thirteen different departments/programs in fall 2014. Currently, CSUCI's hiring processes are undergoing some changes, as faculty and administration consider discipline-specific priorities and timelines.

Although there is no set of unified definitions for cluster hiring, the practice generally involves hiring a group of faculty into one or more departments with the intention of forming research and teaching collaborations in the cohort [see Fla15, SE]. An additional consensus is described in the report Faculty Cluster Hiring for Diversity and Institutional Climate [UUH, Fla15] based on ten geographically diverse public research institutions. One of the recommendations is to "work to ensure early buy-in from department heads and especially deans." In some ways, the fall ' 14 group hire at CSUCI is like a cluster hire in that the administration and faculty were working together as they interviewed several potential faculty members at once. Once hired, we participated in cohort networking activities to become familiar with campus life. However, engaging in research or teaching collaborations as a cohort was not a condition for hire. Nevertheless, our teaching philosophies are closely aligned and our research interests in mathematical biology and mathematical physics allowed the potential for research collaborations to form (see Figure 1).

Special hiring practices such as cluster hiring have been shown to be effective in hiring underrepresented minorities in STEM [Smith]. It is among the hiring practices that "yield hiring across all racial/ethnic groups, suggesting that it would not violate current restrictions in the use of affirmative action" [Smith]. Departments intending to diversify their faculty but worried about affirmative action may consider a cluster-hire approach adapted to their program needs. In this case, it is recommended to obtain administrative buy-in during the hiring process [UUH, Fla15]. Our hire was not initiated at CSUCI with the intention to hire two faculty in mathematics, nor was it a traditional cluster hire. Members from our DSC worked with administration to ensure their approval of our hire. These individuals were aware of the impact that hiring us together would make in supporting our student body. Professor Cynthia Wyels, a member of the Math Program's Disciplinary Search Committee in Spring 2014, states,

Our Math Program was authorized to search for one tenure-track position. We typically forward the top 3-4 candidates' materials to our dean and provost, with some comments indicating program preferences. Like many, our university has been seeking to diversify our faculty for years, with limited success. This year, our top two candidates were Latina. Our administration recognized the value each offered our students, and that hiring both together would immediately create value much greater than the sum of its parts, while also offering these new faculty a potential confidant and partner in their work. The administration found the resources to offer both mathematicians a position, and the rest is happy history!

\section{Impact on Us - and the University}

Since there are two of us, we can validate each other's perspectives as Latinas, allowing for a stronger influence within the university. Being hired into the same department means that we learn about our university culture together; become familiar with the university's retention, tenure, and promotion (RTP) processes together; discuss impressions and perceptions with each other; form strategies for influencing departmental culture at an HSI; and consult with each other and agree to be intentional about the committees we serve on. Although we are both quite busy with service to our department, the university, and the mathematics discipline, having the option to share the amount of work between two people helps to avoid fatigue.

It is well known that female faculty, in particular women from historically underrepresented groups, are often re- 


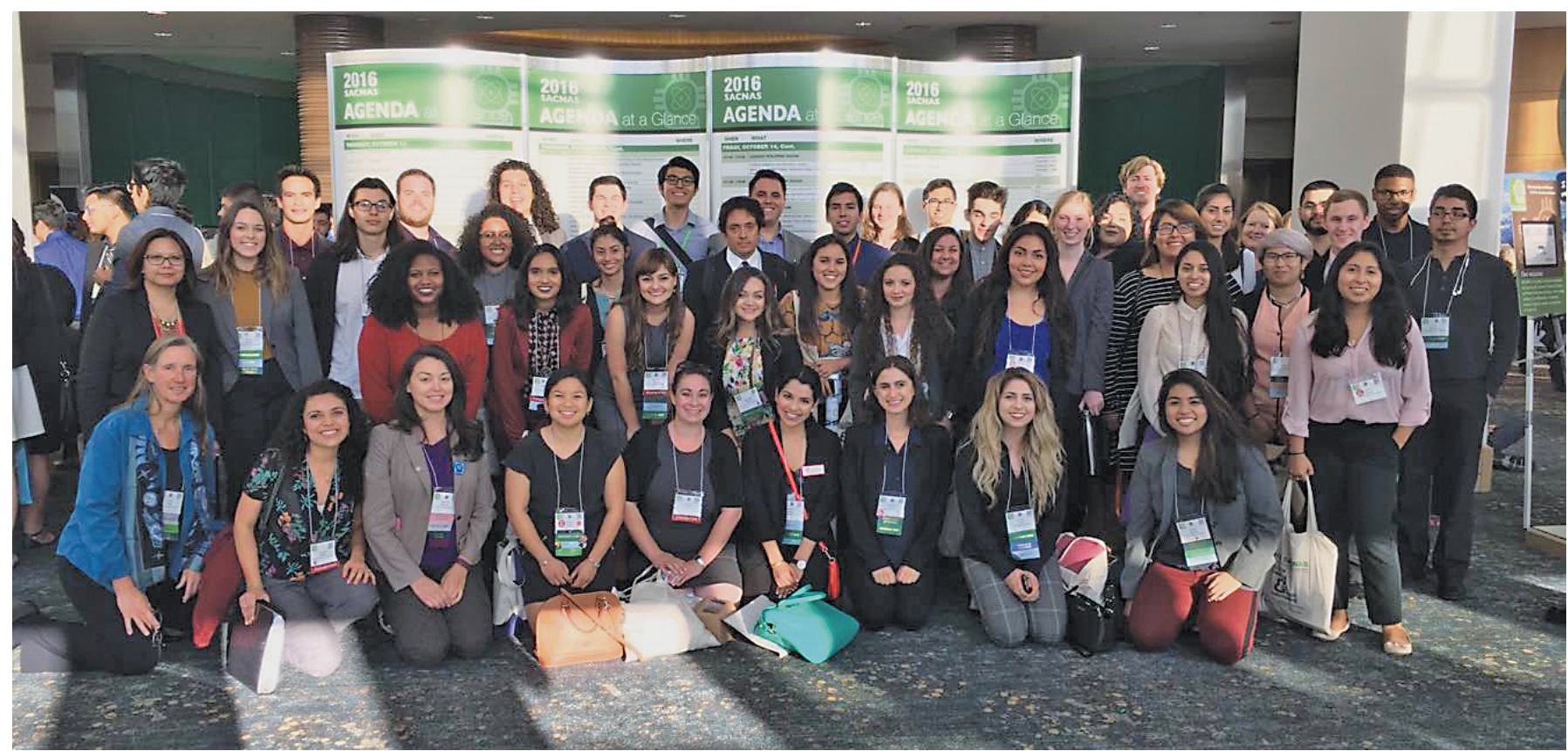

Figure 2. CSUCl students, faculty, and staff at SACNAS 2016 in Long Beach, CA.

quested to serve on several committees at once [GuaBor, Niemann]. Moreover, individual faculty from historically underrepresented groups are susceptible to token-status, which partially describes a person belonging to a numerical minority less than $15 \%$ of the faculty size (see [Niemann] and references therein). Additionally, tokens face isolation from majority colleagues, who may perpetuate unconscious biases; distinctiveness from disproportionate attention due to their token status; and representativeness from the majority perspective that views the collection of tokens as homogeneous, to name a few [Niemann]. That is, the token faculty's words are taken as representing the views of all who belong to their historically underrepresented group, not their viewpoint or opinions as an individual. Many university and professional society committees seek to represent the perspectives of different groups; being female, in STEM, and belonging to an underrepresented minority, we are sought often for committee work or other service calls. We are aware that our contributions to committee work can be viewed as representing the collective ideals of an entire group, and we take on that responsibility. Service work is essential for a university and professional societies to thrive. Unfortunately, the day-to-day university services rarely carry reputational benefits of discipline-specific service and may actively limit research time. Because CSUCI is fairly new and has the second-lowest tenure density in the CSU system at $29 \%$ [Calfac], the need and expectation for tenure-track faculty input and service in university-wide committees is substantial. As assistant professors, much of this university committee work is time-consuming, has little impact on the wider math community, and reduces our opportunities to serve on national/international mathematics committees. In our case, one of the strengths of having a colleague who understands the difficulty in managing service load is that we can remind each other of our individual teaching, research, and service goals in order to avoid accepting service invitations that fall out of line with our priorities. Occasionally we have shared in disciplinary service, but we have not served on university-wide task forces or committees together. While many of our priorities are identical, there is a lot of work to do, so we are able to cover more ground and trust each other when we represent the same interests.

\section{Impact on Students}

During our first spring semester at CSUCI, the Institute of Pure and Applied Math (IPAM) hosted the first LatinX in the Mathematical Sciences Conference. Along with senior faculty colleague Cynthia Wyels, we were able to secure university funds for several students to attend the confer-

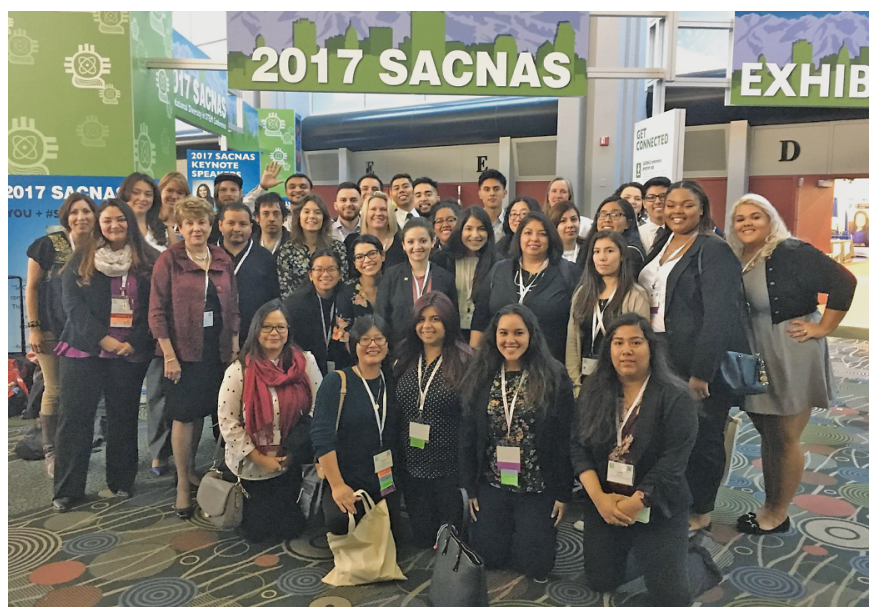

Figure 3. CSUCl team at SACNAS 2017 in Salt Lake City, UT. Institutional commitment is visible with the presence of CSUCI President Erika D. Beck (middle of third row from the bottom). 
ence. This was the first multiday conference for many of our students. Moreover, it was the first conference they attended that featured distinguished Latinx mathematicians. Additional university funds supported students to attend the 2016 and 2017 National SACNAS Conference. The 2016 National SACNAS Conference was held in Long Beach, and we took more than fifty students, staff, and faculty. These efforts are in addition to the university and departmental support provided to students to attend regional MAA and AMS conferences, and the JMM (see Figures 2-5). These activities help students become part of the mathematics community.

We worked together on creating an opportunity for seven of our undergraduate students to engage in funded research during the 2016-2017 academic year (see Figure 6). We applied for and were awarded funds from Preparing Undergraduates through Mentoring for PhDs (PUMP), ${ }^{1}$ the Center for Undergraduate Research in Mathematics (CURM), ${ }^{2}$ and the Foundations of CSU Channel Islands and Brigham Young University. Our personal perspectives allowed us to coordinate supervising research and mentoring a diverse research team during the academic year without becoming overly susceptible to "burnout." The influence of the researchers on their peers, their positive experiences traveling to conferences to present their work, as well as the success in the job market of the graduating seniors (see Figure 7) had a positive effect on the culture around the mathematics department. As a result, many students want to participate in original research and are more aware of postgraduation opportunities. The combination of minority faculty leadership and near-peer success promotes the notion that those from underrepresented groups can flourish within the mathematics discipline. Indeed, "it is crucial to have faculty who are committed to student learning, who reflect in composition the student body, and who have high expectations and are willing to engage in the success of Latino students" [Santiago].

We learned about high-impact teaching practices together as Project NExT fellows (2015 Red Dots). In addition to supervising undergraduate research, we share the strength of implementing new active learning strategies in the classroom. For instance, we incorporate project-based activities, technologies, writing-intensive courses, master-based assessment, and inquiry-based learning activities.

In preparation for this article we sent out a survey with three short-answer questions to thirteen students who know us as instructors, mentors, or research supervisors. The responses were overwhelmingly supportive and thoughtful, and provided insight into students' reactions to our contributions in the department. With too many to include here, we select a few that provide a summary of the collective feedback.

\footnotetext{
1 www . pump-math .org

2 urmath.org/curm
}

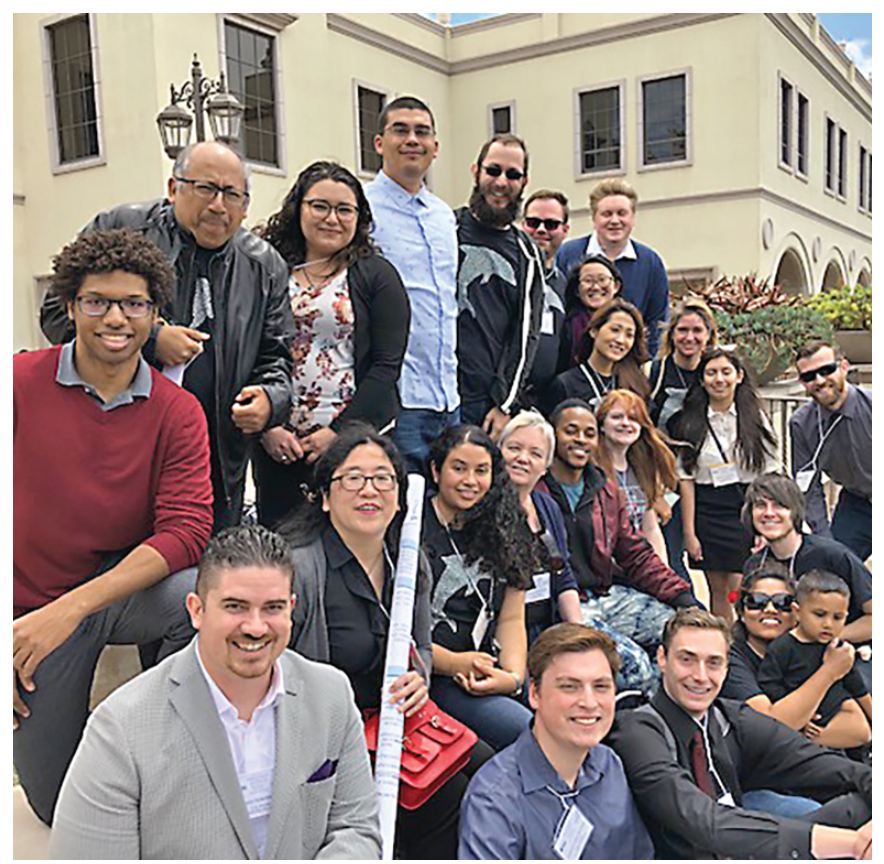

Figure 4. CSUCl math students and faculty at the $2017 \mathrm{MAA}$ regional meeting.

When asked if students noticed any differences in department culture, students responded:

...over these past three years I have noticed a gradual shift in the department towards inclusiveness and diversity-diversity both in composition of the faculty and of the student body with absolutely no degradation in the quality of education provided by the University.

[Drs. Bañuelos and Flores] went above and beyond from teaching multiple math elective classes they felt were essential for students hoping to pursue graduate school, to running clubs that supported students of all races, backgrounds, and genders, to show that anyone can succeed in this field.

When asked if having two Latina faculty/mentors made an impression, students responded:

The fact that they were both Latina gave me the opportunity to communicate with them about my DACA status, and their support was invaluable to me.

I am no mathematical savant so in a field plagued with favoritism, it has been refreshing to work alongside a down-to-earth mentor who can recognize their pupil's interests and difficulties and aid them in understanding complex mathematical concepts. 
Even though I am Desi (South Asian diaspora) and not ethnically underrepresented in mathematics, it was hugely beneficial to have professors who, like me, have overcome obstacles in their academic lives.

They have made the department feel more welcoming and have made other faculty members more aware of how the department can improve.

When asked if they were aware of the statistics showing the gap in representation by Latina faculty in the US, students responded:

...so few Latinas just receiving their doctorates, not to mention how hard it is to become a tenure-track professor! I feel then that our department has won the lottery, having two Latina math $\mathrm{PhD}$ professors, especially ones as exceptionally talented and gifted at both teaching and research as Drs. Flores and Bañuelos. But on a sadder note, this reminds me that they face a lot of professional challenges...

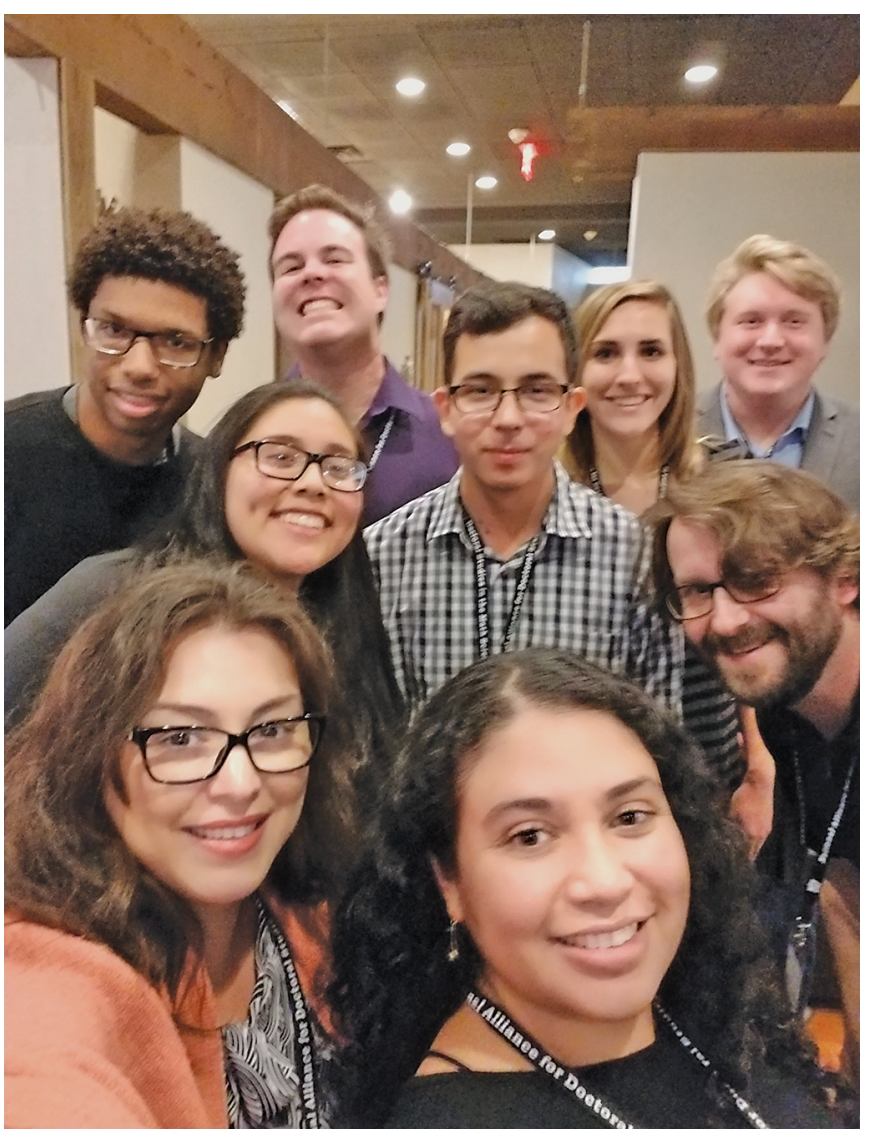

Figure 5. At Field of Dreams:Ty Danet, Garrett Lopez, Andrew Murillo, Kayla Roberts, RobbenTeufel, Nathalie Huerta, John Rock, Selenne Bañuelos, and Cynthia Flores.
It is absurd to find out how low the percentage $(\sim 0.25 \%)$ of Latina Mathematical Sciences PhDs awarded on a yearly basis is. Had I been propositioned to guess an approximate percentage of Latina PhDs I am positive that saying less than one percent wouldn't have been uttered. Perhaps I have been more fortunate than first thought. Having been through a Mathematics Program with two Latina PhDs as professors, in light of the ridiculous low percentage of Latina math PhDs, is simply a revelation.

Lack of diversity is an issue because mathematical innovation can only benefit from a fusion of unique ideas formed by a diverse mathematical community with unique experiences and perspective. So, working with two Latina $\mathrm{PhD}$ faculty has left me with the impression that it is not only possible but necessary to help create a culture in mathematics that encourages more participation and representation of underrepresented minorities in mathematics.

\section{Why lt's Working}

Committee members that made recommendations in [UUH] state the importance of supporting cluster-hired faculty once they are on campus. Indeed, they recommend establishing "infrastructure to support interdisciplinary collaboration, such as hiring faculty in cohorts and holding regular events where informal social networking can occur." The support and opportunities to network that were presented to us as junior faculty made a lasting impact. During our first year at CSUCI we were involved in the Faculty Mentorship Program, where we were assigned a senior faculty member to help us navigate the culture at CSUCI. We met with our mentor one-on-one, and there were also lunches and gatherings with the entire program. A colleague in sociology, Lindsey $\mathrm{O}^{\prime}$ Connor, ran a Professional Development Workshop Series in spring 2015. The materials for the workshop were originally designed to address issues that women face in leadership positions and to provide a set of skills to address these issues. The series covered a range of topics like conveying confidence when public speaking, time management and multitasking, creating effective team dynamics, and creating an inclusive environment. This workshop gave us an opportunity to get to know each other well without other members of our department present.

We were also fortunate to join professional development opportunities outside of campus together. Most notably, we are fellows from the Mathematical Association of America's New Experiences in Teaching 3 (Project NExT)

Www.maa.org/programs-and-communities/professional-development/project-next 
Red '15 Cohort. Project NExT is a selective program that addresses all roles of an academic career. Unfortunately, CSUCI does not have a professional development center for its faculty. We were both eager to learn about best practices for an active learning classroom. Project NExT helped us attain many great ideas and continues to influence how our classes and those of our colleagues function. We also participated in the CURM Workshop on supervising undergraduate research in May 2016. This workshop helped us better prepare to lead our students in research. All of these experiences played an important role in strengthening our small cluster of two Latina math faculty. In a department of ten tenure-track faculty, two female members coming from a historically underrepresented group

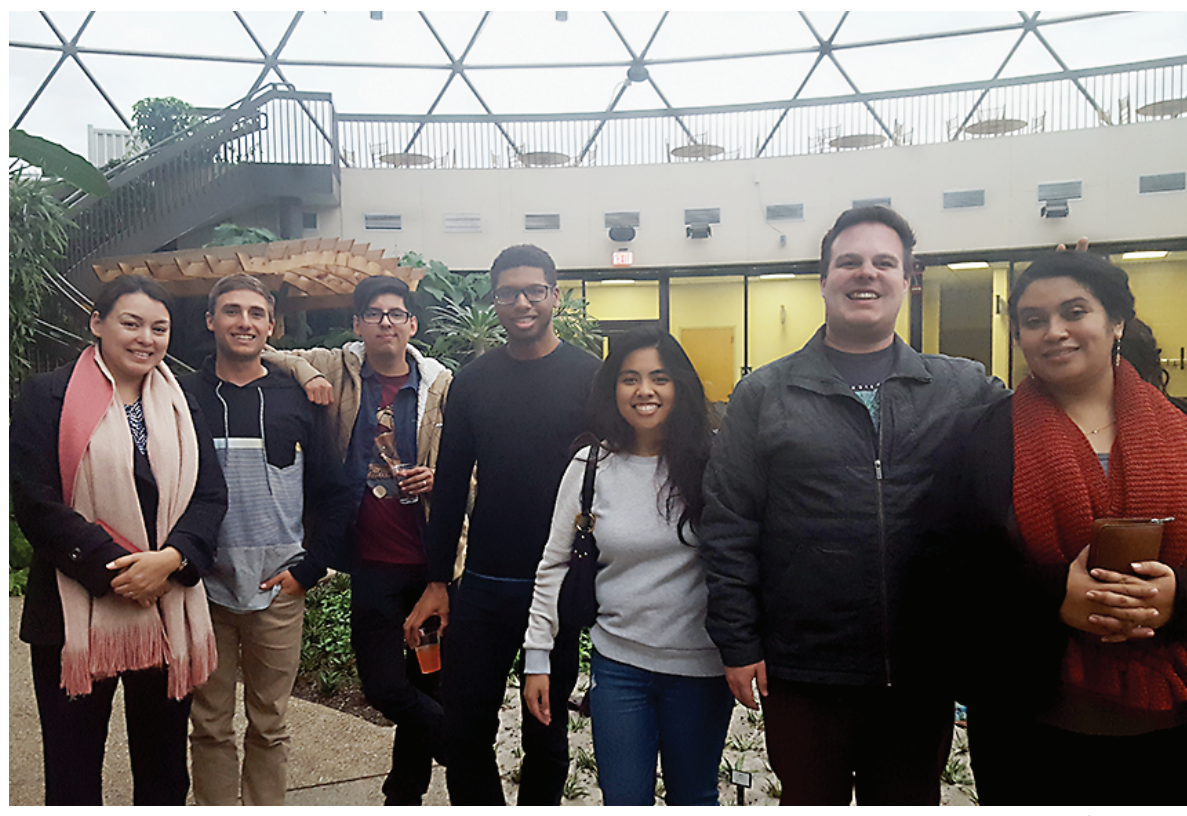

Figure 6. CURM-funded students at Midwest Undergraduate Math Symposium (left to right): Selenne Bañuelos, Matt Costa, Angel Ramos, Ty Danet, Kristen Godinez, Garrett Lopez, and Cynthia Flores.

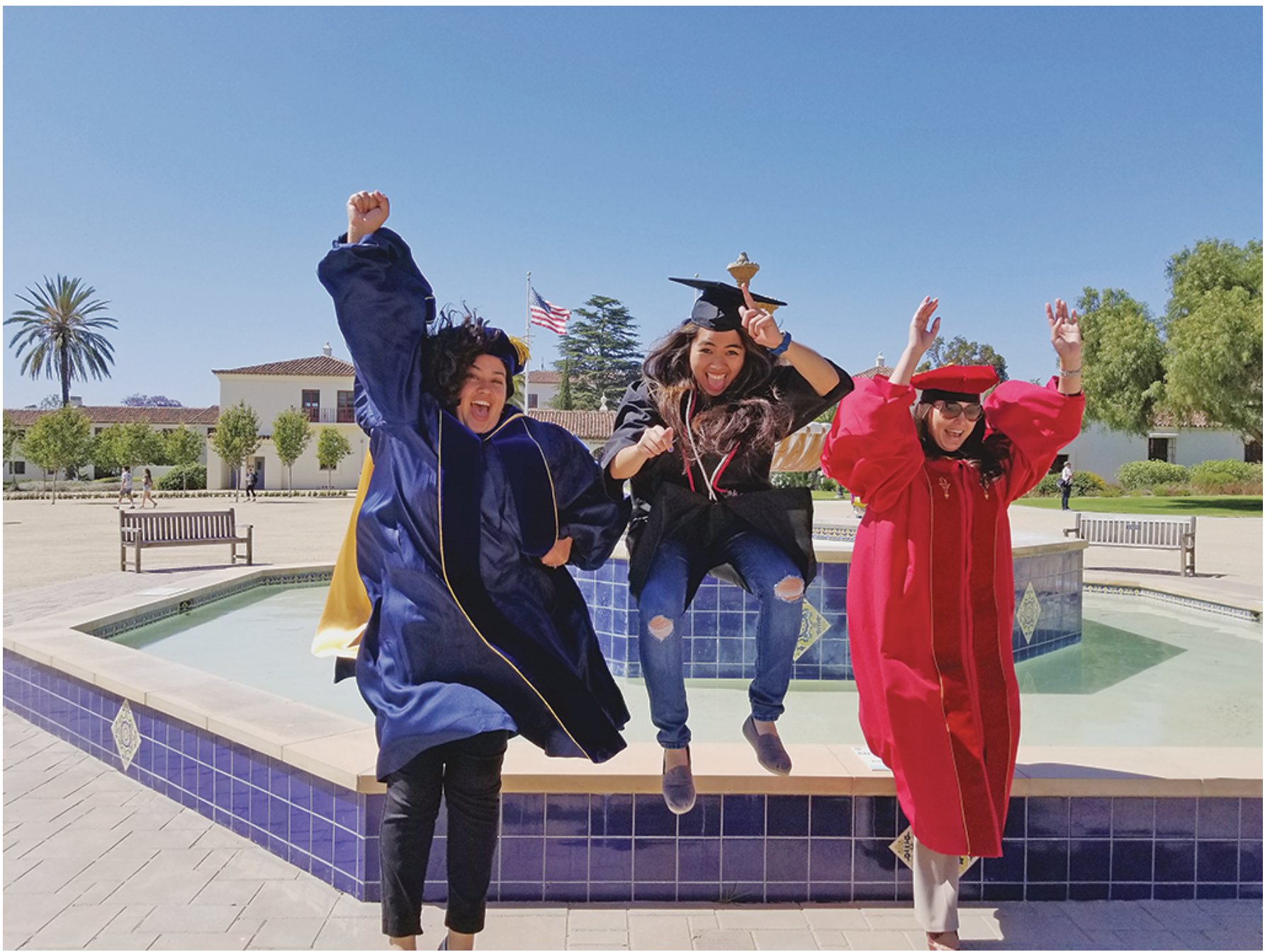

Figure 7. CSUCl 2017 Graduation (left to right): Cynthia Flores, Kristen Godinez, and Selenne Bañuelos. 
have a real chance to promote change that will benefit students. However, we must remain aware that this causes local perception that the work on diversity is somehow done. We note that we are the only two Latina tenure-track faculty in the biology, chemistry, computer science, physics, and mathematics departments.

A drawback that is reported from cluster hiring is that some universities engage in the practice led by their administration and without sufficient consultation at the department level [Fla16]. In these cases the emphasis is placed on how the cluster will work together, not necessarily how they will work in their departments. In particular, "some junior faculty who were hired to do interdisciplinary work were discouraged from doing so because their efforts would not count toward tenure in their home departments" [UUH]. Although the administration made the final decision for our employment, our department intended for us to work in and with members of our department while also encouraging interdisciplinary work in the university.

Our two-person cluster hire is working for us not only because we were hired together but also because we were hired together to serve the students of CSUCI. It was a goal for the both of us to work for an HSI that values diversity and inclusive excellence and values the work that faculty do to help our students. We rely on this shared philosophy to build trust with each other and members from our department, to support our students, and to stay engaged with our mathematics community.

\section{References}

[Velez] Velez WY, Maxwell JW, and Rose C, Report on the 2013-2014 Doctoral Recipients, Notices of the AMS, 62(7) (August 2015), Retrieved from (pg 26): www.ams.org /profession/data/annua 1-survey/2014SurveyNewDoctorates-Report.pdf

[Fla15] Flaherty C, Cluster Hiring and Diversity, Inside Higher Ed, (2015, May 1), Retrieved from: https:// www. insidehighered.com/news/2015/05/01/newreport-says-c1uster-hiring-can-1eadincreased-faculty-diversity

[Fla16] Flaherty C, Cluster-Hiring Cluster \&\%*\#?, Inside Higher Ed, (2016, Feb 1), Retrieved from: https:// www . insidehighered.com/news/2016/02/01/ucriverside-faculty-survey-suggests-outragecluster-hiring-initiative

[SE] Sgoutas-Emch S, Baird L, Myers P, Camacho M, and Lord S, We're Not All White Men: Using a Cohort/Cluster Approach to Diversify STEM Faculty Hiring, Thought \& Action, 32 (1)(2016), Retrieved from: www.nea.org/ home/68489.htm

[UUH] Urban Universities for Health, Faculty Cluster Hiring for Diversity and Institutional Climate, 2015, Retrieved from urbanuniversitiesforhealth.org/media/documents/ Facu1ty_Cluster_Hiring_Report.pdf

[Smith] Smith D, Turner C, Osei-Kofi N, and Richards S, Interrupting the Usual: Successful Strategies for Hiring Diverse Faculty, The Journal of Higher Education, 75(2) (March/ April 2004), 133-160, Retrieved from: www.jstor.org/ stable/3838827

[Niemann] Niemann YF, Diffusing the Impact of Tokenism on Faculty of Color, To Improve the Academy 30 (1)(2011), 216-229.

[GuaBor] Guarino CM and Borden VMH, Faculty Service Loads and Gender: Are Women Taking Care of the Academic Family? Res High Educ (2017) 58: 672. https:// doi .org/10.1007/s11162-017-9454-2

[Calfac] Calfac.org, Tenure Density at CSU Campuses, 2017, Retrieved from: https://www.calfac.org/sites/main/ fi1es/fi1e-attachments/tenure_density_2012-16_ hc_0.pdf

[Santiago] Santiago DA, Taylor M, Galdeano EC, From Capacity to Success: HSIs, Title V, and Latino Students, Excelencia in Education, May 2016, (online) https:// www.edexcelencia.org/research/publications/ capacity-success-hsis-title-v-and-latino-students

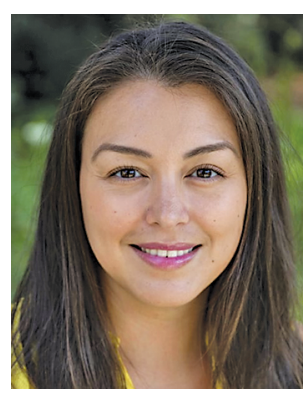

Selenne Bañuelos

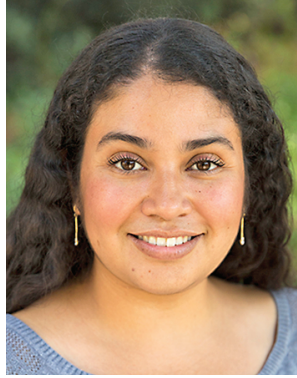

Cynthia V. Flores

\section{Photo Credits}

Figure 1 is by Donald Cole.

Figures 2 and 3 are by Cynthia Wyels.

Figure 4 is by Ivona Grzegorczyk.

Figures 5, 6, and 7 are by Selenne Bañuelos.

Photo of Selenne Bañuelos is courtesy of CSU Channel Islands.

Photo of Cynthia V. Flores is courtesy of CSU Channel Islands. 